\section{SOI: 1.1/TAS DOI: 10.15863/TAS International Scientific Journal Theoretical \& Applied Science}

\author{
p-ISSN: 2308-4944 (print) ｅ-ISSN: 2409-0085 (online) \\ Year: $2015 \quad$ Issue: 09 Volume: 29
}

Published: $30.09 .2015 \quad$ http://T-Science.org

\author{
Kanat Mukashev \\ Professor, DrSc., \\ Kazakh National University after \\ al-Farabi, Almaty, Kazakhstan \\ mukash_kanat@mail.ru
}

Farid Fahrievich Umarov

Professor, DrSc.,

Kazakh-British Technical University, Almaty,

Kazakhstan

farid1945@yahoo.com

\title{
RADIATION-INDUCED EFFECTS AND DEFECTS IN TI -GE ALLOYS
}

Abstract: In this paper we discuss a possibility of using positron spectroscopy method to investigate structural defects in titanium-germanium system. Defects are created by charged particles irradiation. Positrons find themselves sensitive to the radiation defects as a consequence of influence of the latter on the metals electron structure. With the knowledge of positrons behavior and by change of annihilation parameters, one can trace and predict an evolution of structural damages. This information is very important from both perspectives of fundamental problems of radiation defects formation and their accumulation, and development of recommendations for practical use.

Key words: metals, alloys, defects, alpha particles, positron, electron, annihilation.

Language: English

Citation: Mukashev K, Umarov FF (2015) RADIATION-INDUCED EFFECTS AND DEFECTS IN TI -GE ALLOYS. ISJ Theoretical \& Applied Science 09 (29): 144-148.

Soi: http://s-o-i.org/1.1/TAS-09-29-28 Doi: crossef http://dx.doi.org/10.15863/TAS.2015.09.29.28

Introduction. Achievement of the objectives in the radiation damage physics is provided by correct problem statement and competent choice of subjects of inquiry, especially when the investigation is conducted by the positron annihilation method. According to [1], by the degree of cognition of positron capture effect manifestation all metals can be divided into three classes. The first class consisted of 18 elements, which are metals that give evidence of positron capture effect. Another group is comprised of 14 elements including ( $\mathrm{Ti}$ and $\mathrm{Ge}$ ) and forms the second class of metals which have no evidence of positron capture effect. However, it is not clear as per which reasons the authors of [1] attribute one or other metals to classes that exhibit or not evidences of positron capture effect.

On the basis of a comprehensive analysis of these data, the following criterion of selecting a subject of inquiry was developed for investigating the positron annihilation method. Since a careful and critical analysis to verify presence of positron capture effect for all enlisted metals is impossible, it was decided to choose such basic metal among second class elements which would be available in all respects and prospective constructional material. This material must possess the capability to form a binary alloy with elements of both its class and other classes. Titanium meets all these requirements and possess many unique properties that are not observed in other metals. As a second component of making binary alloys the following elements were chosen $\mathrm{Ge}$ (2nd class). For investigating the nature of radiation damage ability with simultaneous positron capture effect establishment, the following alloys were prepared on the basis of titanium iodide, containing $0 ; 1,2 ; 2,5 ; 3,3$; and 4,1 at. $\%$ Ge. The concentrations of the second component were chosen so as to position all alloys in the field of solid solution. The samples had a disc form with the diameter of $15 \mathrm{~mm}$ and thickness of $1 \mathrm{~mm}$. The initial state of the materials was reached by annealing at $\mathrm{T}=900^{\circ} \mathrm{C}$ temperature and vacuum $10^{-7}$ Torr during 1 hour.

Experimental. Since the positron annihilation methods are sensitive generally to the vacancy defects, the goal of our work becomes retention of this type defects in the course of irradiation of the investigated material. The vacancy defects become movable at temperatures above $100^{\circ} \mathrm{C}$ [2]. Therefore, it is necessary to keep the sample temperature not more than the mentioned, which, in principle, is not an intricate problem. The interstitial atoms in these conditions migrate to the sinks and do not have a considerable influence on the investigation results by positron annihilation methods $[3,4]$.

Usually, while irradiating the metals with charged particles the latter lose their energy for forming the radiation defects and sample heating. The samples' temperature is was measured by chromel-alumel thermocouple welding on to the 
built-in edges of $a$ the plate, so during irradiation the thermocouple is was found outside of the irradiation action field. Irradiation of samples by helium ions on isochronous accelerator U-150 was conducted in airbased atmosphere with water-cooled base and forced air or liquid nitrogen vapors blow. At alpha particles irradiation intensity of $(1.5-2) \times 10^{12} \mathrm{~cm}^{-2} \mathrm{c}^{-1}$ and energy $\mathrm{E}=50 \mathrm{MeV}$ the sample's temperature did not exceed $60-70^{\circ} \mathrm{C}$. Having measured the mean value of beam current I, one can determine the particle fluence in the allowed time $t$ or time required for desired dose achievement:

$$
D=6,25 \cdot 10^{12} I t / S,
$$

where $\mathrm{S}$ is the sample's square.

Results and discussion. For interpretation purposes of the investigation results the following annihilation parameters were used: F-redistribution of positron annihilation probability between the conductivity and bound electrons, which is extracted from the spectrum of the annihilation radiation angular correlation and the angle $\theta_{\mathrm{F}}$ respective to the Fermi momentum [2-4]. Kinetics of radiation defects accumulation as a result of the $\alpha$-particles irradiation of $\mathrm{Ti}-\mathrm{Ge}$ alloys system was investigated at fluencies of $10^{14} ; 3.2 \times 10^{14} ; 3.2 \times 10^{15}$ and $10^{16} \mathrm{~cm}^{-2}$. The dosage dependence of the system radiation damageability was investigated at $\alpha$-particles energy $\mathrm{E}=29 \mathrm{MeV}$ and the beam intensity $1.5 \times 10^{12} \mathrm{~cm}^{-2} \mathrm{c}^{-1}$. At the same time, this investigations were repeated at particles energy $\mathrm{E}=50 \mathrm{MeV}$ and $5 \times 10^{15} \mathrm{~cm}^{-2}$ fluence. The samples temperature during the irradiation was sustained in the range of $60-70^{\circ} \mathrm{C}$. After irradiation the angular correlation spectrum was measured followed by its processing and extracting structure sensitive parameters $F$ and $\theta_{\mathrm{F}}$ as well as their relative changes $\Delta \mathrm{F}$ and $\Delta \theta_{\mathrm{F}}$. The results of the investigation are shown in Table 1. It is not difficult to observe that with the fluence growth the annihilation parameters behavior appreciably changes starting from its lowest level $-10^{14} \mathrm{~cm}^{-2}$. The steady growth of the positron annihilation probability and, therefore, the positron capture efficiency with the fluence growth occurs, practically, for all investigated alloys.

The largest values of the positron capture efficiency is observed at $\alpha$-particles irradiation with the energy of $E=50 \mathrm{MeV}$, results of which are also shown in Table 1 for comparison purposes. Meanwhile the particles fluence was smaller by a factor of ten than at $\alpha$-particles irradiation with $\mathrm{E}=29 \mathrm{MeV}$. One can observe a comparatively uniform decrease of the Fermi angle $\theta_{\mathrm{F}}$ at the irradiation fluence increase for the first two compositions. Whereas, for Ti-3.1 at.\% Ge alloy its gradual increase is observed after usual decrease at first two fluence values: $10^{14}$ and $3.2 \times 10^{14} \mathrm{~cm}^{-2}$.
Fermi angle is reaches the value of $\theta_{\mathrm{F}}=5.87 \mathrm{mrad}$ at $10^{16} \mathrm{~cm}^{-2}$ fluence. But this value is remains lower than that for the annealed state $\theta_{\mathrm{F}}=6.0 \mathrm{mrad}$. Of course, the initial decrease $\theta_{\mathrm{F}}$ in this case is associated apparently with a creation of defects with lower electron density. The following increase of $\theta_{\mathrm{F}}$ with fluence increase can be caused by radiation annealing, but in this case the $\mathrm{F}$ parameter must be decrease, which is not observed in practice. Therefore, it should probably be assumed that development of radiation damages in this alloy precipitation of particles initiation is accompanied as a result of supersaturated solid solution decomposition. According to [5,6] at the Ti-3.1 at.\% Ge alloy decomposition the $\mathrm{Ti}_{5} \mathrm{Ge}_{3}$ phase is created. The electron density of such precipitation of particles must vary from that of $\alpha-$ and $\beta-$ Ti. Therefore, simultaneous increase of parameters $\mathrm{F}$ and $\theta_{\mathrm{F}}$ at high doses ene can indicate on positrons capture by the precipitated phase particles.

Analysis of the results of irradiating Ti alloys containing 0.8 and 1.5 at. $\%$ Ge indicates full identity of $\mathrm{F}$ and $\theta_{\mathrm{F}}$ parameters behavior, for which there is no tendency for saturation at the increase of $\alpha$ particles fluence to up to $10^{16} \mathrm{~cm}^{-2}$. If we assume that the $\alpha$-particles fluence increase involves only positrons trapping centers concentration growth in these alloys, then this fact should not have influence on $\theta_{\mathrm{F}}$ value. Decrease of the Fermi angle $\theta_{\mathrm{F}}$ with fluence increase at constant tendency to increasing annihilation probability $F$, one can interpret only by reasonable positrons capture by traps efficiency increase. Probably these traps in this case can be the vacancy-impurity bound states, the capture efficiency of which must be higher than that for simple vacancy defects and their aggregation. The general increment of $\mathrm{F}$ annihilation parameter $\mathrm{F}$ at $\mathrm{E}=29 \mathrm{MeV}$ and fluence increase from $10^{14}$ to $10^{16} \mathrm{~cm}^{-2}$ was equal $\Delta \mathrm{F}$ $=173 \%$ for alloy contained 0.8 at. $\%$ Ge. For the second alloy $\mathrm{Ti}-1.8$ at. $\% \mathrm{Ge}$ the increment is equal $148 \%$ and for the last case - about $88 \%$. Such tendency is also observed for Fermi angle change (Table 1). It is important to note that this regularity is remains at alloys irradiation by $\alpha$-particles with higher energy $\mathrm{E}=50 \mathrm{MeV}$, but probability increment $\Delta F$ in each case is equal to $200 ; 181$ and $105 \%$ at fluence constant value of $5 \times 10^{15} \mathrm{~cm}^{-2}$.

Of course, in order to achieve such values of annihilation parameter at $\mathrm{E}=29 \mathrm{MeV}$, it is necessary to increase fluence to yet another order from attained level $10^{16} \mathrm{~cm}^{-2}$. Therefore, at constant value $\theta_{\mathrm{F}}=5.57$ mrad for all three alloys derived at irradiation by higher energy the considerable increase of $\Delta F$ (nearly 1.8 times) is becomes the reason of the respective increase of the radiation defects concentration.

This circumstance makes it possible to suppose that the radiation defects in investigated materials possess similar configuration in a given energy 


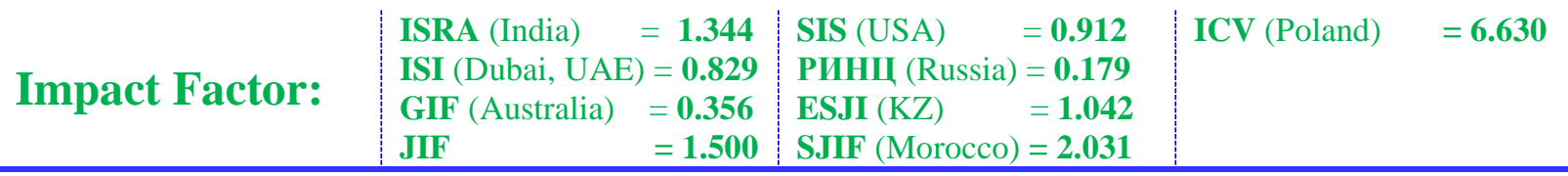

range. But, a considerable increase of the positron capture efficiency by parameter $\mathrm{F}$ with changing bombarding particles energy indicated on nuclear reactions role in the processes of radiation-induced defect formation in materials [7].

The $\alpha$-particles fluence and energy influence on Ti-Ge annihilation parameters.

Table 1

\begin{tabular}{|c|c|c|c|c|c|c|}
\hline $\begin{array}{c}\text { Composition, } \\
\text { at. \% }\end{array}$ & $\begin{array}{c}\text { Energy } \\
\text { MeB }\end{array}$ & $\begin{array}{c}\text { Fluence, } \\
\mathrm{cm}^{-2}\end{array}$ & $F$ & $\begin{array}{c}\Delta F \\
\%\end{array}$ & $\begin{array}{c}\theta_{F}, \\
\text { mrad. }\end{array}$ & $\begin{array}{c}\Delta \theta_{F} \\
\%\end{array}$ \\
\hline \multirow{5}{*}{ Ti-0,8 Ge } & - & annealed & 0.26 & - & 6.40 & - \\
& 29 & $10^{14}$ & 0.32 & 23 & 5.82 & 6.2 \\
& 29 & $5 \cdot 10^{14}$ & 0.48 & 85 & 5.68 & 11.2 \\
& 29 & $10^{15}$ & 0.50 & 92 & 5.80 & 9.4 \\
& 29 & $5 \cdot 10^{15}$ & 0.55 & 112 & 5.57 & 10.9 \\
\cline { 2 - 7 } & 50 & $10^{16}$ & 0.71 & 173 & 5.39 & 15.8 \\
\hline \multirow{5}{*}{ Ti-1,5 Ge } & - & $5 \cdot 10^{15}$ & 0.78 & 200 & 5.57 & 10.9 \\
& 29 & $10^{14}$ & 0.27 & - & 6.33 & - \\
& 29 & $5 \cdot 10^{14}$ & 0.35 & 30 & 6.00 & 5.2 \\
& 29 & $10^{15}$ & 0.40 & 48.1 & 5.83 & 7.9 \\
& 29 & $5 \cdot 10^{15}$ & 0.51 & 89 & 5.48 & 13.4 \\
\cline { 2 - 7 } & 50 & $5 \cdot 10^{15}$ & 0.67 & 107 & 5.57 & 12.0 \\
& - & annealed & 0.41 & 181 & 5.39 & 14.8 \\
\hline \multirow{5}{*}{ Ti-3,1 Ge } & 29 & $10^{14}$ & 0.47 & 145 & 6.00 & - \\
& 29 & $5 \cdot 10^{14}$ & 0.56 & 37 & 5.76 & 4.0 \\
& 29 & $10^{15}$ & 0.52 & 27 & 5.57 & 7.2 \\
& 29 & $5 \cdot 10^{15}$ & 0.60 & 46 & 5.83 & 5.7 \\
\cline { 2 - 7 } & 50 & $10^{16}$ & 0.77 & 88 & 5.87 & 2.8 \\
\hline Accuracy \pm & & $5 \cdot 10^{15}$ & 0.84 & 105 & 5.57 & 7.2 \\
\hline
\end{tabular}

It should be noted that the radiation activity of materials by dosimetry control results is considerably higher at $\mathrm{E}=50 \mathrm{MeV} \alpha$-particles irradiation than after irradiation with $\mathrm{E}=29 \mathrm{MeV}$. Therefore, the obtained values of the annihilation parameters received for $\mathrm{Ti}$ alloys irradiated by $\alpha$-particles are not maximum and be found still rather far from saturation.

One can estimate radiation defects accumulation kinetics in Ti-Ge alloys in dependence on $\alpha$-particles fluence by positron capture efficiency changing, which is determined by capture coefficient:

$$
\mathrm{K}=\left(\mathrm{F}_{\alpha}-\mathrm{F}_{0}\right) /\left(\mathrm{F}_{\mathrm{m}}-\mathrm{F}_{\alpha}\right),
$$

where $F_{\alpha}$ is a current value of the parameter; $F_{0}$ is the parameter value for material's annealed state; $F_{m}$ is a maximum value of parameter's in investigated interval.

The nature of the parameter's change in dependence on $\alpha$-particles fluence for $\mathrm{Ti}$ (1) and $\mathrm{Ti}$ 3.1 at.\% Ge is presented in Fig.1. It is evident that the positron capture efficiency increases for the concerned materials approximately with the same rate and changing nature practically does not depend on concentration of the alloying element. At the same time the growth rate of $\mathrm{K}$ coefficient for alloy is lower than that for Ti. Apparently, the reason for this can be the radiation defects configuration change that leads to the respective redistribution of electron density in damaged regions. 


\begin{tabular}{|c|c|c|c|c|c|c|}
\hline Impact Factor: & $\begin{array}{l}\text { ISRA (India) } \\
\text { ISI (Dubai, UAE } \\
\text { GIF (Australia) } \\
\text { JIF }\end{array}$ & $\begin{array}{l}=1.344 \\
=0.829 \\
=0.356 \\
=1.500\end{array}$ & $\begin{array}{l}\text { SIS (USA) } \\
\text { PИНЦ (Russia) } \\
\text { ESJI (KZ) } \\
\text { SJIF (Morocco) }\end{array}$ & $\begin{array}{l}=0.912 \\
=0.179 \\
=1.042 \\
=2.031\end{array}$ & ICV (Poland) & $=6.630$ \\
\hline
\end{tabular}

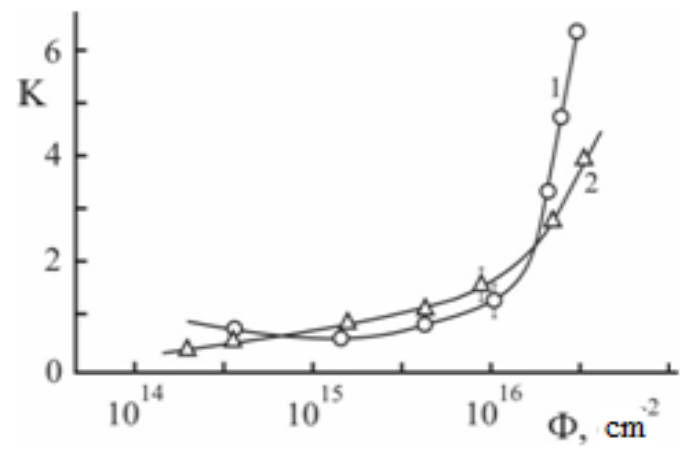

Figure 1 - Dose dependence of positron capture efficiency for $\mathrm{Ti}(1)$ и $\mathrm{Ti}-3.1$ at.\% Ge (2) alloys.

In the fluences interval $10^{14} \div 5 \cdot 10^{15} \mathrm{~cm}^{-2}$ the positron capture efficiency growth rate is significantly lower than at fluences exceeding $5 \times 10^{15} \mathrm{~cm}^{-2}$. This field corresponds to the incubation period of radiation defects accumulation, at rather higher values of which the defects accumulation process grows up rapidly. But, since the defects in this case are of vacancy nature, the initial accumulation obey the clusterization principle and furthermore can form microvoids. The microvoids' specific character is their critical radius which is reached by way of fluctuating at the expense of point defects absorption. Consequently the microvoids grow in dimensions intensively. But not all microvoids reach the critical radius simultaneously and, if this is the case, the new stage of the swelling process begins, that is the small voids dissolution by the large voids. The vacancies and interstitial atoms that are nascent simultaneously under irradiation diffuse to the sinks. If interstitial atoms are captured by voids then their growth rate becomes slower sharply, which involves the change of the voids distribution function by dimensions. In this case the metal volume change in the swelling process is described by the following expression [8]:

$V(t)=A\left(D_{V} C_{V} R_{S}\right)^{1 / 3} \sqrt{G \cdot \rho_{d}\left(Z_{i}-Z_{V}\right)} \cdot t^{5 / 6}$ (3)

It is evident from this equation that the swelling process depends on (i) irradiation temperature $\mathrm{V} \sim\left(\mathrm{D}_{\mathrm{V}} \mathrm{C}_{\mathrm{V}}\right) /^{1 / 3}$; (ii) defects generation rate $\mathrm{V} \sim \sqrt{G}$ and (iii) irradiation time $\mathrm{V} \sim \mathrm{t}^{5 / 6}$. Therefore, in the course of irradiation time swelling increases without saturation factors, which we observed in this case (Fig.2). It is obvious that this process is more efficient when the metal packing defect energy is even lower. The investigated $\mathrm{Ti}$ alloys belong to this class of materials. This circumstance is well manifested in electron density distribution nature, which we will describe in what follows.

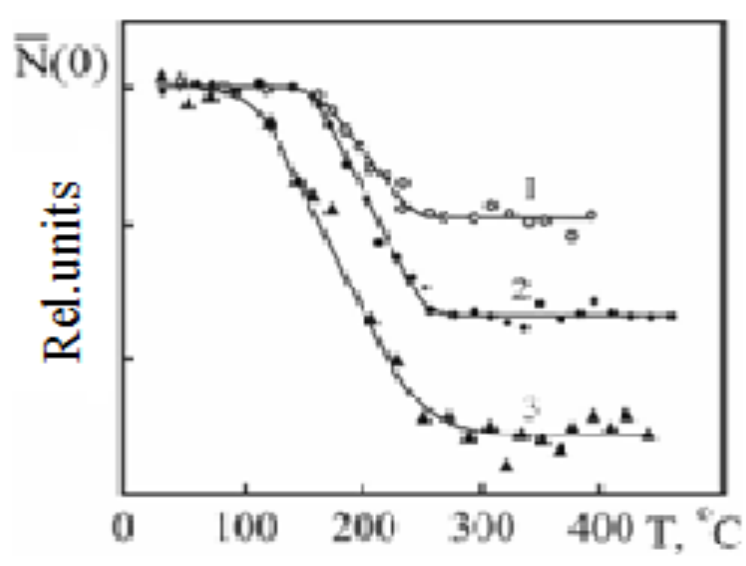

1. $\mathrm{E}=29 \mathrm{MeV}, \Phi=5 \times 10^{15} \mathrm{~cm}^{-2} ; \quad 2 . \mathrm{E}=29 \mathrm{MeV}, \Phi=5 \times 10^{16} \mathrm{~cm}^{-2} ; 3 . \mathrm{E}=50 \mathrm{MeV}, \Phi=5 \times 10^{15} \mathrm{~cm}^{-2}$

Figure 2 - The defects annealing in Ti - 3.1at.\% Ge alloys, irradiated by $\alpha$ - particles with different energy and fluence. 
The configuration similarity of radiation defects in alloys generated under $\alpha$-particles irradiation becomes apparent in isochronal annealing results, presented in Fig.2. One can see that regardless the $\alpha$ particles fluence and energy of the latter, only one return stage is observed, which proves occurrence of only one type of structure damages in alloys. Increase in both fluence (from $5 \times 10^{15}$ to up to $10^{16}$ $\mathrm{cm}^{-2}$ ) and energy (from 29 to up to $50 \mathrm{MeV}$ ) causes boost of defects concentration. Some tightened nature of annealing stage completion of $\alpha$-particles irradiation at $\mathrm{E}=50 \mathrm{MeV}$ in comparison with $\mathrm{E}=29$ $\mathrm{MeV}$ represents a consequence of own attributes in characteristics. Here, we are talking about radiation damages configurations created at the expense of elastic interactions without formation of vacancies clouds subcascades (at $\mathrm{E}_{\alpha}=29 \mathrm{MeV}$, curves 1,2 ) and at the expense of the same elastic interactions with formation of considerable subcascades and nuclear reactions $\left(\mathrm{E}_{\alpha}=50 \mathrm{MeV}\right.$, curve 3$)$.

At the same time the radiation defects migration activation energy values found by above mentioned technique for investigated alloys: $\mathrm{E} a_{1}=$ $1.40-1.42 \mathrm{eV}$ - for the first case and $\mathrm{E} a_{2}=1.50-$ $1.55 \mathrm{eV}$ - for the second case, serve as evidence of indicated assumptions. In addition, from analysis of the presented annealing curves one can extract another imperative information. The higher the radiation defects concentration in alloy, the lower the annealing temperature. That is, with fluence increase (from $5 \times 10^{15}$ to up to $10^{16} \mathrm{~cm}^{-2}$ ) at constant energy of $\alpha$-particles ( $29 \mathrm{MeV}$ ) or energy increase (from 29 to up to $50 \mathrm{MeV})$ at constant fluence $\left(5 \times 10^{15} \mathrm{~cm}^{-2}\right)$ the beginning of return is shifted towards low temperatures. Probably, with increase of point defects concentration in crystal, those potential barriers descend, which prevent the activation processes related to ions movement. Along with this, evidently, the bound energy between them is decreasing. The latter in turn is leads to a decrease of the temperature threshold of defects migration and this fact is reflected on the isochronal annealing curves. The full annealing of the structure damages in alloy, irradiated by $\mathrm{E}=29 \mathrm{MeV} \alpha$-particles, is completed in the temperature ranges near $300^{\circ} \mathrm{C}$.

Summary. Formation and accumulation of the radiation origin structure defects can render a considerable influence on the positron capture probability in metals and alloys of Ti-Ge system. With this viewpoint, the titanium alloys with high content of germanium, at which the abnormally high annihilation parameter change under high energy $\alpha$ particles influence are observed, should be considered as the least steady in respect to radiation damageability. Therefore, on the basis of the finding one can assume that irradiation, as well as deformation, can initiate such structure damages, capture potential of which for positrons is much larger than for simple defects such as vacancy and dislocation type. But radiation phenomena that accompany these transformations are obviously presented for thermalized positrons, the deeper potential wells of capture, than those which accompany polymorphic transformations initiated by deformation.

\section{Acknowledgement}

The authors would like to thank Dr. Umarov T.F. for his very useful help.

\section{References:}

1. Tanigawa S, Hinode K, Owada N, Doyama M (1979) The phenomenological Interpretation of positron lifetime and Trapping effect in metals with the special reference to the state of Hydrogen. Proc. 5th. Int. Conf. of Positron Annihilation. Japan, Tokyo. (1979) 159 - 165.

2. Mukashev KM, Tronin BA (2010) Defects of hydrogenous origin in refractory metals alloys and positron annihilation. Izvestiya Vuzov, Ser. Fizika. Tomsk. (2010) 55-58.

3. Mukashev KM (2009) Slow positrons physics and positron spectroscopy. Almaty, 2009.

4. Mukashev KM, Umarov FF (2007) Hydrogen behaviour in electron-irradiated titanium alloys studied by positron annihilation method. Rad.
Effects and Defects in Solids. 162 (2007) 415423.

5. Novoselova AV (1987) Phase diagrams, construction and investigation methods. Moscow, 1987.

6. Quillan M (1956) Titanium. Bettelworth, 1956.

7. Gindin IA, Lapiashvili ES (1978) The radiation defects influence on processes of titanium programmed strengthening. Reactor material science. TSNIIAtominform. 2 (1978) 317-343.

8. Ibragimov SS, Reutov VF, Vagin SP, Botvin KV (1987) The radiation damages in Mo, irradiated by protons and $\alpha$-particles. Fizika and XOM. 1 (1987) 3-9. 